\title{
Risk of disability and mortality due to overweight in a Finnish population I/
}

\author{
Aila|Rissanen, MarkkulHeliövaara, PaulKnekt, Antti Reunanen, ArpolAromaa, Jouni Maatela
}

Abstract

Objective-To investigate the effect of overweight on premature mortality and work disability in young and middle aged Finns.

Design-Prospective cohort study based on data collected in the multiphasic health examinations by the Social Insurance Institution of Finland from 1966 to 1972 and follow up until 1982.

Setting-34 Communities throughout Finland.

Subjects-12 053 Women and 19076 men who were employed and aged 25-64 at baseline.

Main outcome measures-Mortality and work disability pensions from all and specified causes.

Results-Body mass index was a weak predictor of death but a strong predictor of early work disability, which increased linearly with body mass index. After adjustment for age, geographical region, occupation, and smoking the relative risks of work disability for women and men with a body mass index $\geqslant 30 \mathrm{~kg} / \mathrm{m}^{2}$ were, respectively, $2.0(95 \%$ confidence interval 1.8 to 2.3$)$ and $1.5(1.3$ to 1.7$)$ when compared with those of subjects with body mass index $<22.5 \mathrm{~kg} / \mathrm{m}^{2}$. The increased risks were due to an excess of cardiovascular and musculoskeletal diseases but not of mental diseases. One fourth of all disability pensions from cardiovascular and musculoskeletal causes in women and half as many in men could be attributed to overweight (body mass index $>25 \mathrm{~kg} / \mathrm{m}^{2}$ ) alone.

Conclusions-Though modest overweight has little impact on mortality it predicts severe functional impairment. A considerable proportion of work disability pensions could probably be prevented by efficient weight control.

Research Institute for - Social Security, Social Insurance Institution, _PO Box 78, SF-00381 Helsinki, Finland]

Aila Rissanen, MD, research officer

Markku Heliövaara, MD, research officer

Antti Reunanen, MD, research officer

Paul Knekt, DRPH, research officer

Arpo Aromaa, MD, director, medical research group

Rehabilitation Research Centre, Social Insurance Institution, SF-00381

Helsinki, Finland

Jouni Maatela, MD, chief

physician, mobile clinic unit

Correspondence to:

Dr Rissanen.

Br Med f 1990;301:835-7 weight and height were measured in light indoor clothing. ${ }^{3}$ Body mass index, defined as weight $(\mathrm{kg})$ divided by height squared $\left(\mathrm{m}^{2}\right)$, was used to estimate the degree of overweight.

The mortality of the participants was followed up continuously by checking death certificates obtained for all the deceased from the Central Statistical Office of Finland. This report covers the deaths occurring until the end of 1982. The follow up period for mortality refers to the period of observation from the initial examination until age 65 (the general age of retirement in Finland), death occurring before age 65, or the end of 1982. An analysis of the mortality of the entire study cohort of the Social Insurance Institution's health survey has been presented elsewhere. ${ }^{45}$

Data on new disability pensions granted to the participants were collected from the institution's pension register by using the unique personal identification number to link the records. The primary diagnosis in the doctor's certificate for the persistent disability pension was taken as the cause of disability. Al disability pensions granted up to the end of 1982 were included in the study. The follow up period refers to the period of observation from the initial examination until early retirement, the age of 65 , death before age 65 , or the end of the observation period. The average follow up period for mortality and disability was 11 years.

An exponential log linear survival model ${ }^{6}$ was used to analyse the significance of body mass index as an independent predictor of work disability and mortality. Age, geographical region, occupation, and smoking were included in the model as potential confounding factors. As well, adjusted relative risks and their $95 \%$ confidence intervals were estimated by the model.

\section{Results}

Altogether 2096 deaths occurred and 4706 new disability pensions were granted in the population of 31129 during the 346000 person years of follow up (table I).

The risk of work disability increased linearly with increasing body mass index in both women and men, whereas overall mortality showed only a slight curvilinear association with weight (figure). After adjustment for the effects of age, geographical region, occupation, and smoking the relative risks of death were $1.0(95 \%$ confidence interval 0.7 to 1.3$)$ for women and $1.2(0.9$ to 1.4$)$ for men with body mass index $\geqslant 30 \mathrm{~kg} / \mathrm{m}^{2}$, compared with the risks of subjects ubjects and methods

Between 1966 and 1972 a representative sample examined in multiphasic health surveys by the mobile clinic of the Social Insurance Institution of Finland in parts of the country. ${ }^{2}$ Information abo sociodemographic background, habits, lifestyle, and health of the participants was collected by standard examinations, interviews, and questionnaires. ${ }^{2}$ Body \begin{abstract}
Population attributable fractions ${ }^{7}$ were calculated on the basis of the relative risks and the prevalence of various degrees of overweight estimated on the basis of the model. The population attributable fraction was used to estimate the proportion of disability and mortality that could be prevented by eliminating the underlying harmful trait.

Overweight reduces longevity, mainly through an effect on related diseases.
course and cause considerable functional disability not consequently may underestimate the importance of
\end{abstract} overweight to health and wellbeing. To obtain a more
comprehensive view of the problem we studied the role invalidity pension, probably one of the best indicators invalidity pension, probably
for early functional disability. 
whose body mass index was $<22.5 \mathrm{~kg} / \mathrm{m}^{2}$. The corresponding risks of work disability for similarly overweight women were $2.0(1.8$ to 2.3$)$ and for men were $1.5(1.3$ to 1.7$)$. In women, $22 \%$ of overall premature work disability was attributable to excess weight (body mass index $\geqslant 25.0 \mathrm{~kg} / \mathrm{m}^{2}$ ) alone and $10 \%$ could be attributed to body mass index $\geqslant 30 \mathrm{~kg} / \mathrm{m}^{2}$. In men, the corresponding attributable fractions were $9 \%$ and $4 \%$.

Overweight strongly predicted disability pensions granted on the basis of cardiovascular and musculoskeletal diseases (table II), with $25 \%$ of all disability pensions from these causes in women being attributable solely to body mass index $\geqslant 25 \mathrm{~kg} / \mathrm{m}^{2}$. The corresponding attributable fractions in men were $15 \%$ and $11 \%$. Weight did not predict work disability from mental diseases.

\section{Discussion}

These results show that the toll of overweight on health well exceeds that measured in terms of mortality. Even modest overweight, which has little impact on longevity, significantly predicted premature functional impairment of the cardiovascular and locomotor systems, as evidenced by an excess of work disability pensions, probably the best indicators available for such impairment. Work invalidity pension is granted to a Finn under age 65 whose capacity to work is found to be reduced by at least $40 \%$ in a scrutinised review of all available patient data including a detailed physician's certificate.

The increased risk of disability of overweight people is caused by an increased incidence of diseases related to obesity, in particular cardiovascular diseases and arthroses,' which were the main medical causes of disability in our study cohort. The risk of disability from mental causes was not increased among overweight Finns, confirming the impression that few important differences exist in the mental health of overweight and normal weight people in the general population. ${ }^{8}$ Part of the high risk of disability from overweight is due to other associated problems such as diminished exercise tolerance and social or psycho-

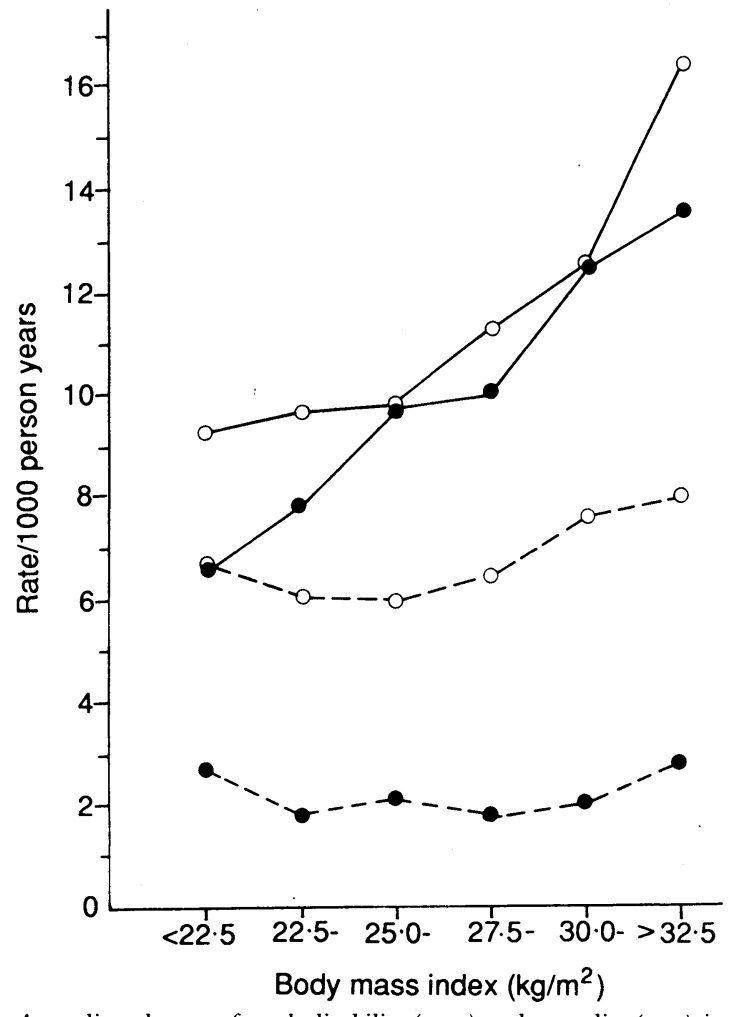

Age adjusted rates of work disability (---) and mortality (-) in women $(\bullet)$ and men $(\circ)$

logical disadvantages, ${ }^{9}$ which constitute a severe and mostly hidden burden of overweight.

For the overweight person, the excess weight thus denotes an increased risk of morbidity, lowered quality of life, and loss of earnings. For society, overweight denotes increased health expenditure per person and loss of productivity due to disability. These adverse consequences could be avoided. Overweight is amenable to medical intervention, but more effective treatment strategies are needed. ${ }^{10}$ The prevention of overweight holds a great promise. The present results

TABLE I - Relative risk of premature work disability and mortality from all causes according to body mass index

\begin{tabular}{|c|c|c|c|c|c|c|c|c|c|c|}
\hline \multirow[b]{3}{*}{$\begin{array}{l}\text { Body mass index } \\
\left(\mathrm{kg} / \mathrm{m}^{2}\right)\end{array}$} & \multirow[b]{3}{*}{$\begin{array}{l}\text { Total } \\
\text { No }\end{array}$} & \multicolumn{4}{|c|}{ Women } & \multicolumn{5}{|c|}{ Men } \\
\hline & & \multicolumn{2}{|c|}{ Disability pension } & \multicolumn{2}{|r|}{ Death } & \multirow[b]{2}{*}{$\begin{array}{l}\text { Total } \\
\text { No }\end{array}$} & \multicolumn{2}{|c|}{ Disability pension } & \multicolumn{2}{|r|}{ Death } \\
\hline & & No & $\begin{array}{l}\text { Relative risk } \\
\text { (95\% confidence } \\
\text { interval) }\end{array}$ & No & $\begin{array}{c}\text { Relative risk } \\
\text { (95\% confidence } \\
\text { interval })\end{array}$ & & No & $\begin{array}{l}\text { Relative risk } \\
\text { (95\% confidence } \\
\text { interval) }\end{array}$ & No & $\begin{array}{c}\text { Relative risk } \\
\left(\begin{array}{c}95 \% \text { confidence } \\
\text { interval })\end{array}\right. \\
\end{array}$ \\
\hline$<22 \cdot 5$ & 3032 & 229 & $1 \cdot 0$ & 79 & $1 \cdot 0$ & 3644 & 536 & $1 \cdot 0$ & 358 & $1 \cdot 0$ \\
\hline $22 \cdot 5-24 \cdot 9$ & 2981 & 334 & $1.2(1.0$ to 1.4$)$ & 69 & $0.7(0.5$ to 0.9$)$ & 5750 & 814 & $1.0(0.9$ to 1.2$)$ & 470 & $0.9(0.8$ to 1.0$)$ \\
\hline $25 \cdot 0-27 \cdot 4$ & 2584 & 413 & $1.5(1.3$ to 1.7$)$ & 87 & $0.8(0.6$ to 1.1$)$ & 5359 & 803 & $1 \cdot 1(1.0$ to 1.2$)$ & 452 & $0.9(0.8$ to 1.0$)$ \\
\hline $27 \cdot 5-29 \cdot 9$ & 1683 & 297 & $1.5(1.3$ to 1.8$)$ & 52 & $0.7(0.5$ to 1.1$)$ & 2839 & 519 & $1.2(1.1$ to 1.4$)$ & 276 & $1.0(0.8$ to 1.1$)$ \\
\hline $30 \cdot 0-32 \cdot 4$ & 995 & 235 & $1.9(1.6$ to 2.3$)$ & 38 & $0.7(0.5$ to 1.1$)$ & 1065 & 217 & $1.4(1.2$ to 1.6$)$ & 121 & $1.1(0.9$ to 1.4$)$ \\
\hline$\geqslant 32.5$ & 778 & 203 & $2 \cdot 1(1.7$ to 2.5$)$ & 42 & $1.1(0.7$ to 1.6$)$ & 419 & 106 & $1.8(1.4$ to $2 \cdot 2)$ & 52 & $1.2(0.9$ to 1.6$)$ \\
\hline p Value for trend: & & & $<0.0001$ & & 0.866 & & & $<0.0001$ & & 0.221 \\
\hline $\begin{array}{l}\text { Linear } \\
\text { Curvilinear }\end{array}$ & & & $\begin{array}{c}<0.0001 \\
0.883\end{array}$ & & $\begin{array}{l}0.806 \\
0.012\end{array}$ & & & 0.613 & & 0.014 \\
\hline
\end{tabular}

^Adjusted for age, geographical region, smoking, and occupation by including these variables in the log linear model.

TABLE II - Relative risk (adjusted for age, sex, occupation, region, and smoking) of work disability by body mass index. Numbers in parentheses are numbers of disability pensions granted

\begin{tabular}{|c|c|c|c|c|c|c|c|}
\hline \multirow[b]{2}{*}{ Cause of disability } & \multicolumn{6}{|c|}{ Body mass index $\left(\mathrm{kg} / \mathrm{m}^{2}\right)$} & \multirow{2}{*}{$\begin{array}{l}\mathrm{p} \text { Value for } \\
\text { linear trend }\end{array}$} \\
\hline & $<22 \cdot 5$ & $22 \cdot 5-24 \cdot 9$ & $25 \cdot 0-27 \cdot 4$ & $27 \cdot 5-29 \cdot 9$ & $30 \cdot 0-32 \cdot 4$ & $\geqslant 32.5$ & \\
\hline Cardiovascular diseases & $1 \cdot 0(227)$ & $1 \cdot 2(399)^{\star}$ & $1 \cdot 3(416)^{\star}$ & $1 \cdot 5(301)^{\star \star \star}$ & $2 \cdot 2(194)^{\star \star \star}$ & $2 \cdot 5(123)^{\star \star \star}$ & $<0.0001$ \\
\hline Coronary heart disease & $1.0(127)$ & $1 \cdot 2(216)$ & $1.4(241)^{\star \star}$ & $1 \cdot 5(161)^{\star \star \star}$ & $1 \cdot 8(83)^{\star \star \star}$ & $1 \cdot 6(40)^{\star \star}$ & $<0.0001$ \\
\hline Stroke & $1.0(34)$ & $0.8(40)$ & $0.7(34)$ & $1 \cdot 1(32)$ & $1.5(18)$ & $1 \cdot 2(8)$ & 0.327 \\
\hline Other & $1.0(66)$ & $1.5(143)^{\star \star}$ & $1.4(141)^{\star \star}$ & $1.8(108)^{\star \star \star}$ & $3 \cdot 1(93)^{\star \star \star}$ & $4 \cdot 2(75)^{\star \star \star \star}$ & $<0.0001$ \\
\hline Musculoskeletal diseases & $1.0(215)$ & $1 \cdot 2(358)^{\star}$ & $1.4(413)^{\star \star \star}$ & $1.5(276)^{\star \star \star}$ & $1.7(160)^{\star \star \star}$ & $1.9(114)^{\star \star \star}$ & $<0.0001$ \\
\hline Diseases of back & $1.0(137)$ & $1 \cdot 2(224)$ & $1 \cdot 4(260)^{\star \star \star}$ & $1.6(175)^{\star \star \star}$ & $1.8(97)^{\star \star \star}$ & $1 \cdot 4(48)^{\star}$ & $<0.001$ \\
\hline Arthroses of knee and hip & $1 \cdot 0(38)$ & $1 \cdot 2(72)$ & $1 \cdot 6(91)^{\star}$ & $1.7(66)^{\star \star \star}$ & $2 \cdot 3(48)^{\star \star \star \star}$ & $3 \cdot 6(48)^{\star \star \star}$ & $<0.001$ \\
\hline Mental diseases & $1 \cdot 0(90)$ & $1 \cdot 0(116)$ & $1 \cdot 2(136)$ & $1 \cdot 2(78)$ & $1 \cdot 1(34)$ & $1 \cdot 1(21)$ & $0 \cdot 230$ \\
\hline Respiratory diseases & $1 \cdot 0(90)$ & $0.7(78)^{\star \star \star}$ & $0.6(75)^{\star \star \star}$ & $0.6(39)^{\star \star}$ & $0.6(17)^{\star}$ & $0.6(10)$ & 0.006 \\
\hline Accidents & $1 \cdot 0(27)$ & $1 \cdot 2(47)$ & $0.8(27)$ & $1.5(30)$ & $1 \cdot 1(9)$ & $1 \cdot 7(7)$ & 0.628 \\
\hline
\end{tabular}

${ }^{\star} \mathrm{p}<0 \cdot 05,{ }^{\star \star} \mathrm{p}<0 \cdot 01,{ }^{\star \star \star} \mathrm{p}<0 \cdot 001$. 
indicate that a substantial proportion of all premature work disability pensions would not have been necessary with efficient weight control. Contrary to the widely held belief, " the benefits of preventing overweight seem to be greater in women than in men, at least in terms of the preservation of functional capacity.

Preventing overweight would have had only a negligible effect on mortality in the present study population; this confirms the results of several studies that document only a weak association between high body weight and mortality. ${ }^{12}$ It is not entirely clear why overweight conveys a clearly increased risk of disability without affecting mortality. Overweight may be associated with some beneficial or protective traits favouring survival, but the possible extra years of life are likely to be of poor quality and of limited value.

In the present study the body mass index associated with the smallest risk of work disability, and presumably with the best health, was lower than that associated with the greatest longevity, the customary basis for defining desirable or ideal weight. ${ }^{13}$ The value of weight standards based on longevity rather than on the quality of life should be seriously questioned.

Can the results of this study be generalised? The study cohort was large and representative of the occupationally active and presumably healthy ${ }^{14}$ Finnish population, ${ }^{2}$ the attendance rate in the study was good, ${ }^{2}$ and the ascertainment of deaths ${ }^{4}$ and disability was complete. The data should therefore allow fairly unbiased conclusions to be drawn about the impact of body weight on the health of employed Finns. No comparable data are, to the best of our knowledge, available from other countries, and in view of the complex interplay of multiple cultural factors in determining weight on one hand and health on the other the Finnish results may not necessarily be applicable elsewhere. Even so, the similarity of living conditions and the high prevalence of overweight in Finland ${ }^{3}$ and in other industrialised countries ${ }^{15}$ suggest that overweight may have similar health implications in other populations.

We conclude that overweight is not an innocuous condition but a major preventable and treatable cause of ill health and disability in affluent populations.

\footnotetext{
1 Simopoulos AP, van Itallie TB. Body weight, health, and longevity. Ann Intern Med 1984;100:285-95.

2 Reunanen A, Aromaa A, Pyörälä K, et al. The Social Insurance Institution's coronary heart disease study. Acta Med Scand 1983;suppl 673:1-120.

3 Rissanen A, Heliövaara M, Aromaa A. Overweight and anthropometric changes in adulthood: a prospective study of 17000 Finns. Int $f$ Obes 1988;12:329-39.

4 Rissanen A, Heliövaara M, Knekt P, et al. Weight and mortality in Finnish men. Fournal of Clinical Epidemiology 1989;42:781-9.

5 Rissanen A, Knekt P, Heliövaara M, et al. Weight and mortality in Finnish women. fournal of Clinical Epidemiology (in press).

6 Kalbfleisch JD, Prentice RL. The statistical analysis of failure time data. New Yalbfleisch JD, Prentice

York: Wiley, 1980.
Miettinen OS. Proportion of disease caused or prevented by a given exposure, trait or intervention. Am f Epidemiol 1974;99:325-32.

8 Wadden TA, Stunkard AJ. Social and psychological consequences of obesity. Ann Intern Med 1985;103:1062-7.

9 Stewart AL, Brook RH. Effects of being overweight. Am J Public Healt 1983;7:171-8.

10 Bennett W. Dietary treatments of obesity. Ann NY Acad Sci 1987;499:250-63.

11 Anonymous. Men, women, and obesity [Editorial]. Br Med $\mathcal{F}$ 1974;iv:249-50.

12 Mason JE, Stampfer J, Hennekens CH, Willett WC. Body weight and longevity. FAMA 1987;257:353-8.

13 Harrison G. Height-weight tables. Ann Intern Med 1984;100:989-94.

14 Vinni K, Hakama M. Healthy worker effect in the total Finnish population. Brf Ind Med 1982;8:153-8.

15 Millar WJ, Stephens TS. The prevalence of overweight and obesity in Britain, Canada, and United States. Am F Public Health 1987;77:38-41.

(Accepted 29 fune 1990)
}

\title{
Trial of brief intermittent neuroleptic prophylaxis for selected schizophrenic outpatients: clinical and social outcome at two years
}

\author{
A G Jolley, S R Hirsch, E Morrison, A McRink, L Wilson
}

Department of Psychiatry, Charing Cross Hospital, London W6 8RF A G Jolley, MRCPSYCH, consultant psychiatrist

Department of Psychiatry, Charing Cross and Westminster Medical School, London W6 8RF S R Hirsch, FRCPSYCH, professor of psychiatry

E Morrison, RMN, community psychiatric nurse

A McRink, RMN, community psychiatric nurse

$\mathrm{L}$ Wilson, $\mathrm{MRCPSYCH}$, research worker

Correspondence to:

Professor Hirsch.

BrMed f 1990;301:837-42

\section{Abstract}

Objective-To evaluate a novel approach to the prophylaxis of schizophrenic relapse characterised by administration of brief courses of neuroleptic for the earliest non-psychotic signs of relapse (prodromal symptoms).

Design - Two year follow up of subjects randomised, double blind, to receive either active (control group) or placebo (intermittent group) depot neuroleptic medication. Both groups received brief courses of oral neuroleptic when prodromal symptoms or relapse occurred.

Setting-Psychiatric outpatient department, Charing Cross Hospital, London.

Subjects -54 Stable patients in remission who met the American Psychiatric Association's DSM-III criteria for schizophrenia on the basis of case notes.

Main outcome measures-Survival without relapse, survival without hospitalisation, point prevalence of extrapyramidal side effects and tardive dyskinesia, structured assessment of social functioning (social adjustment scale II), and frequency of prodromal symptoms.

Results - Of 19 relapses recorded over two years, $10(53 \%)$ were preceded by non-psychotic prodromal signs. Survival rates for both relapse and hospitalisation were worse with intermittent treatment than continuous treatment over the two year follow up: $92 \%$ of controls and only $54 \%$ of patients given intermittent treatment survived the two year period without hospitalisation. Prolonged or frequent relapses as well as episodes of prodromal symptoms were more frequent with intermittent treatment. Lower scores for extrapyramidal side effects were recorded in the intermittent treatment group, but periodic assessments of social functioning failed to show any social advantages from this.

Conclusion-The findings are at variance with a previous report of one year follow up in this cohort and attest to the superiority of continuous depot neuroleptic prophylaxis in preventing both psychotic and neurotic or dysphoric morbidity in schizophrenia.

\section{Introduction}

Over the past decade concern has mounted over the adverse effects of neuroleptic drugs used in the prophylaxis of schizophrenic relapse. This strategy is well known to reduce the risk of exacerbating symptoms, ${ }^{1}$ but many authors have highlighted the wider context in which outcome of treatment for the condition should be evaluated and have pointed to potentially deleterious consequences of drug exposure for patients' general wellbeing and social adjustment. Of principal concern have been the occurrence of tardive dyskinesia and distressing extrapyramidal side effects - these side effects have been linked to 